\title{
Traumatic reopening of macular hole following successful surgical repair
}

\author{
This article was published in the following Dove Press journal: \\ International Medical Case Reports Journal \\ 3 March 2017 \\ Number of times this article has been viewed
}

\author{
Margaret Wong \\ Robert L Halpern \\ James H Frank \\ Vitreoretinal Department, Eye \\ Consultants of Atlanta, Atlanta, \\ GA, USA
}

Correspondence: Margaret Wong Eye Consultants of Atlanta, 3225 Cumberland Boulevard, Suite 800, Atlanta, GA 30339, USA

Tel +l 7703299478

Fax +l 4043554955

Email margaret.oph@gmail.com
Abstract: A 75-year-old Caucasian female with a full-thickness macular hole underwent a successful surgical repair. Vision improved from 20/400 to 20/30 after surgery. Two years later, the patient presented with a decreased vision after a fall onto her face with a reopened fullthickness macular hole. Vision decreased to 20/400 and then she underwent a second surgery with an internal limiting membrane peeling, which resulted in a second successful closure of her macular hole. Vision following the second surgery was 20/100. Reopening of a surgically repaired macular hole commonly follows cataract surgery, epiretinal membrane formation, and development of cystoid macular edema. This case demonstrates that surgically repaired macular holes may reopen after trauma as well.

Keywords: macular hole, reopening, trauma

\section{Introduction}

Macular hole reopening after successful surgical repair is well documented in the literature, and it is commonly caused by cataract surgery, growth of an epiretinal membrane (ERM), and development of cystoid macular edema (CME). ${ }^{1,2}$ However, there has been no documentation to our knowledge of traumatic reopening of a successfully repaired macular hole. We present a patient whose surgically repaired macular hole reopened following trauma.

\section{Case report}

A 75-year-old Caucasian female presented with a decreased vision in her left eye. Examination showed 20/400 vision, nuclear sclerotic cataract, and a full-thickness macular hole. The macular hole was an evident on optical coherence tomography (OCT) (Figure 1). The patient underwent successful cataract extraction followed by macular hole repair. The macular hole was repaired with pars plana vitrectomy, attempted internal limiting membrane (ILM) peeling without staining agent, perfluoropropane $\left(\mathrm{C}_{3} \mathrm{~F}_{8}\right)$ gas, and 2 weeks of face down positioning. The macular hole closed completely, which was shown on the postoperative OCT done 8 weeks following surgery (Figure 2). Vision improved to 20/30. The patient did well for 2 years until she presented after a fall onto her face and decreased vision in the left eye. There were facial ecchymoses bilaterally, but no other serious injuries. Vision decreased to 20/400 and a full-thickness macular hole was again seen on examination and OCT (Figure 3). The OCT also showed a small ERM nasal to the hole. Six weeks later, repeated pars plana vitrectomy and ILM peeling were performed with brilliant blue stain, and the patient again had $\mathrm{C}_{3} \mathrm{~F}_{8}$ 


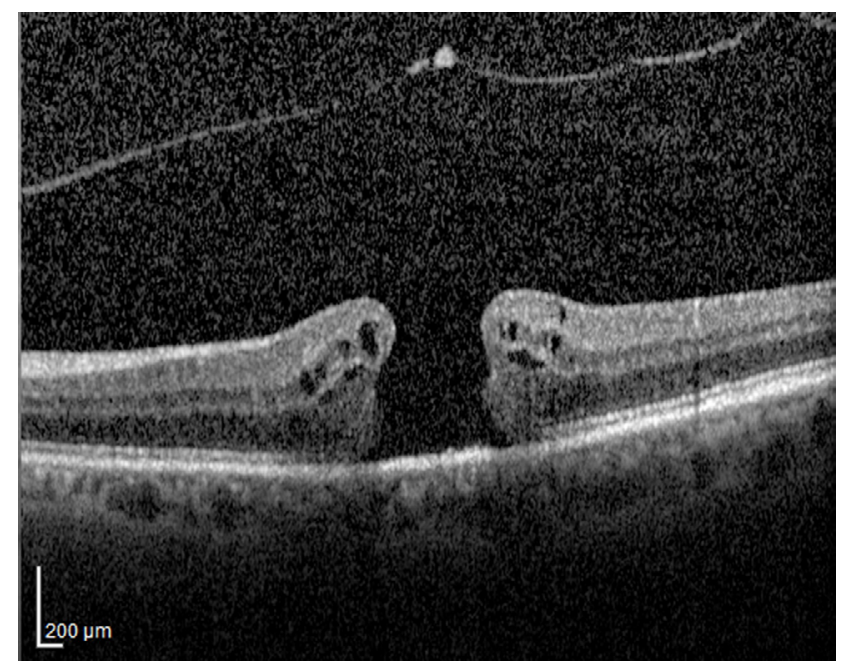

Figure I Preoperative optical coherence tomography showing full-thickness macular hole.

Note: The hole measures $\sim 375 \mu$.

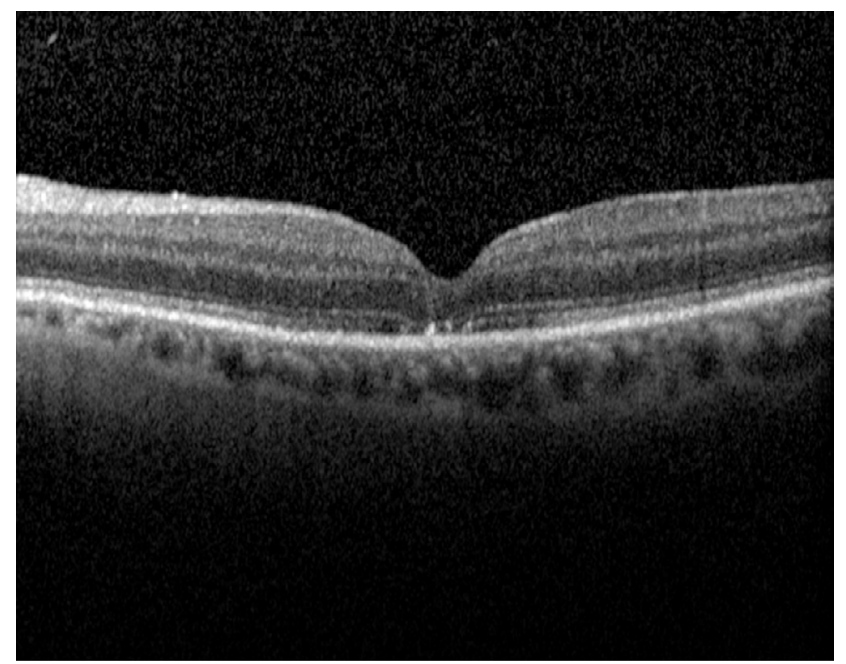

Figure 2 Postoperative optical coherence tomography showing successful closure of the macular hole with a normal foveal depression.

Note: However, there is disruption of the subfoveal ellipsoid zone.

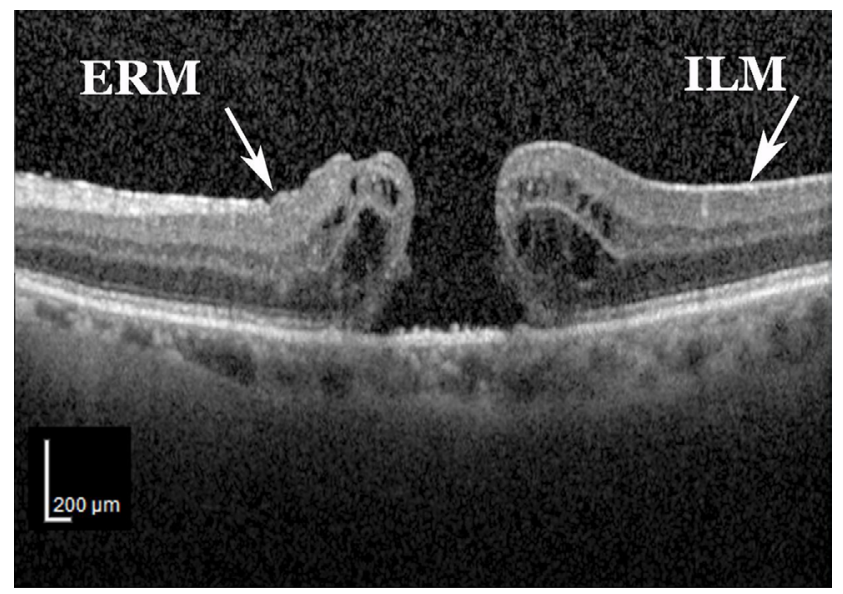

Figure 3 Post-traumatic optical coherence tomography showing a full-thickness macular hole.

Notes: The ILM is present on the retina temporal to the hole. There is a small ERM nasal to the hole. The hole measures $\sim 400 \mu$.

Abbreviations: ERM, epiretinal membrane; ILM, internal limiting membrane.

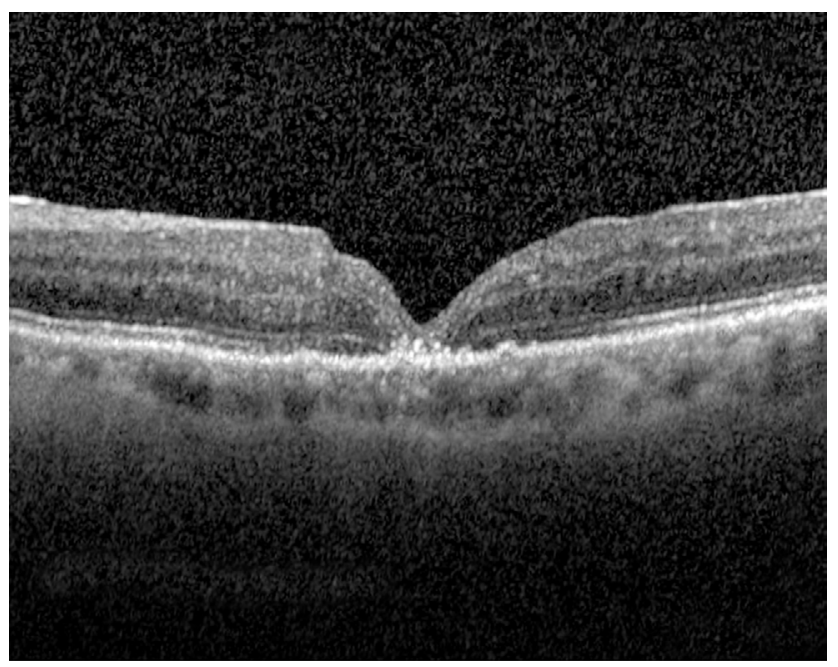

Figure 4 Postoperative optical coherence tomography showing successful closure of macular hole following trauma.

Note: There is again disruption of the subfoveal ellipsoid zone.

gas and 2 weeks of face down positioning. The macular hole was closed following the second surgery (Figure 4), and the patient's vision improved to 20/100 6 weeks postoperatively.

The patient provided written informed consent for the publication of this case report.

\section{Discussion}

There are three well-known factors that contribute to reopening of a surgically repaired macular hole: cataract surgery after the macular hole repair, growth of an ERM, and development of CME. ${ }^{1,2}$ In addition, Bartolini et al described a case of macular hole reopening after successful surgical repair 12 years later, which could have been caused by incomplete ILM removal. ${ }^{3}$ The incidence of macular hole reopening following successful surgical repair appears to be between $2 \%$ and $6.9 \%{ }^{1,46}$ However, there has been no documentation to our knowledge of reopening of a surgically repaired macular hole secondary to trauma. In our case, the reopening occurred 2 years following successful surgical repair of the macular hole and immediately following the trauma. In addition to the trauma, there may also be an additive effect of incomplete peeling of the ILM during the first surgery due to the fact that no staining agent was used. Another compounding factor in the hole reopening could be the development of a small ERM nasal to the macular hole. The macular hole closed again following the complete ILM peel during the second vitrectomy. Our case highlights trauma as a possible contributing mechanism of macular hole reopening following the previous successful surgical repair. Ophthalmologists should be aware of the possibility of traumatic reopening of macular holes, which may help in preoperative patient education. 


\section{Acknowledgment}

The authors would like to thank Mr Ray S Swords for ophthalmic photography.

\section{Disclosure}

The authors report no conflicts of interest in this work.

\section{References}

1. Paques M, Massin P, Santiago P, Spielmann AC, LeGargasson J, Gaudric A. Late reopening of successfully treated macular holes. Br J Ophthalmol. 1997;81(8):658-662.
2. Paques M, Pascale M, Pierre B, Duquesnoy A, Gaudric A. Long-term incidence of reopening of macular holes. Ophthalmology. 2000;107(4): 760-766.

3. Bartolini CE, Goldman DR, Duker JS. Late reopening of an initially successfully closed macular hole after 12 Years. Retin Cases Brief Rep. 2014; $8(1): 30-32$.

4. Christmas NJ, Smiddy WE, Flynn HW. Reopening of macular holes after initially successful repair. Ophthalmology. 1998;105(10):1835-1838.

5. Banker AS, Freeman WR, Kim JW, Munguia D, Azen SP. Visionthreatening complications of surgery for full-thickness macular holes. Ophthalmology. 1997;104(9):1442-1453.

6. Duker JS, Wendel R, Patel AC, Puliafito CA. Late re-opening of macular holes after initially successful treatment with vitreous surgery. Ophthalmology. 1994;101(8):1373-1378.

\section{Publish your work in this journal}

The International Medical Case Reports Journal is an international, peer-reviewed open-access journal publishing original case reports from all medical specialties. Previously unpublished medical posters are also accepted relating to any area of clinical or preclinical science. Submissions should not normally exceed 2,000 words or

Submit your manuscript here: https://www.dovepress.com/international-medical-case-reports-journal-journal

4 published pages including figures, diagrams and references. The manuscript management system is completely online and includes a very quick and fair peer-review system, which is all easy to use. Visit $\mathrm{http}: / / \mathrm{www}$. dovepress.com/testimonials.php to read real quotes from published authors. 